\title{
Cycles of gametogenesis and planulation in the coral Pocillopora damicornis
}

\author{
J. A. Stoddart \& R. Black \\ Department of Zoology, University of Western Australia, Nedlands, W. A. 6009, Australia
}

\begin{abstract}
Sequence and timing of gametogenesis, embryogenesis and planulation by the coral Pocillopora damicornis at Rottnest Island, the southern limit of the coral's distribution in Western Australia, were examined by an intensive histological analysis. These corals are simultaneous hermaphrodites in which gametogenesis and planulation occur during spring and summer (Nov to Mar) and follow a lunar cycle. Reproductive cycles of gametogenesis and planulation by individual heads are synchronized within and, to a lesser extent, between sites. Individual heads of coral may have up to 3 cycles of maturing gametes and planulae per season. However, despite the intensive histological examination of gametogenesis, the developmental pathway leading to brooded planulae remains equivocal because oogenesis does not necessarily occur in synchrony with planulation.
\end{abstract}

\section{INTRODUCTION}

Recent works on the reproduction of corals by Fadlallah (1983) and Harrison et al. (1984) point out that the past emphasis on species which brood young is not the result of the predominance of the brooding mode of larval development within scleractinians in general. Rather, the emphasis results from the ease of detection of both planulae and planulation that has made such species attractive for studies of reproduction. However, many of the reproductive characteristics of brooding species remain enigmatic despite the attention paid to them (references in Fadlallah 1983). One possible reason for this is that the appearance of planulae is so pervasive a feature, that many studies have not gone past descriptions of planulation in characterizing a species' reproduction. This has led to a situation where many generalizations have been based on inadequate data. Even in Pocillopora damicornis, arguably one of the most studied of corals, the generally accepted theory that brooded planulae are the end result of a sexual process, involving the internal fertilization of ova by broadcast sperm (Hyman 1940, Connell 1973, Campbell 1974, Rosen 1981), has been recently questioned (Stoddart 1983).

\footnotetext{
- Present address: Australian Institute of Marine Science, PMB No. 3, Townsville M. C., Qld. 4810, Australia

Stoddart (1983) demonstrated that the brooded planulae of Pocillopora damicornis in both Western Australia and Hawaii are produced asexually because young are genetically identical to their parent. Nevertheless, the genetical composition of populations of $P$, damicornis is compatible with an additional input from sexually-produced recruits (Stoddart 1983, 1984a). On occasion then, the gonads of this species must either function in sexual reproduction that does not involve brooded planulae, or produce a planula sexually. This discovery of the dual mode of reproduction, involving brooded planulae and gonads, is not unique among anthozoans and parallels the situation in the anemones Actinia tenebrosa (Black \& Johnson 1979) and Actinia equina (Orr et al. 1982). In each of these situations the process which is especially unclear is the relationship between gonadal development and planular production.

This study of Pocillopora damicornis from Western Australia attempts to clarify the species' reproductive characteristics by an intensive and extensive histological analysis conducted by repeatly sampling individually identified heads from 2 populations. In particular, our study addresses questions concerning (1) sequence of gametogenesis, especially the connection between gametes and planulae; (2) timing of gametogenesis; (3) synchrony of reproduction amongst heads within and between populations; (4) number of times a head reproduces per season. 


\section{MATERIALS AND METHODS}

Samples. Samples were obtained from heads of Pocillopora damicornis at Salmon Point and Mary Cove, Rottnest Island, Western Australia $\left(32^{\circ} \mathrm{S}\right.$, $\left.115^{\circ} 30^{\prime} \mathrm{E}\right)$, under 2 collection regimes. Initially, samples of 20 heads were taken at approximately monthly intervals from 10 Jan 1980 until 26 Oct 1982 at Salmon Point. Then, on 24 Nov 1982, 20 heads were mapped and tagged at this site and samples from each taken at intervals of from 4 to $30 \mathrm{~d}$ until 5 Apr 1983. These were called the PSP series. In the same manner, 11 heads from Mary Cove were sampled individually from 17 Aug 1982 to 5 Apr 1983. These were called the PMC series. All tagged heads were initially over $6 \mathrm{~cm}$ in diameter.

Sampling involved breaking about $10 \mathrm{~cm}$ from the end of one branch from each head. On many occasions these were then kept individually in seawater overnight to detect shedding of planulae. After this, or directly after collection, the terminal 1 to $2 \mathrm{~cm}$ of either end of the branch was trimmed to leave approximately $5 \mathrm{~cm}$ of the intermediate segment, which was placed in Bouin's fluid. Branches were trimmed to eliminate non-reproductive tissue from samples, as both Harrigan (1972) and Stimson (1978) found intermediate branch segments to be more fecund than either tips or bases of branches.

Technique. Pieces of coral were decalcified over a number of weeks in one or two changes of Bouin's fluid. A layer of tissue was then removed from the underlying skeleton and embedded in paraffin wax. Tangential sections were cut at $6 \mu \mathrm{m}$ thickness and stained using Gill's haematoxylin and alcoholic eosin. During light microscopy of sections, sperm and ova were both classified into 4 sequential stages (see 'Results'). An estimate of the abundance of these stages was made by counting the number of polyps containing each stage. Approximately 40 to 60 polyps were examined for each coral head. After a stage had been recorded in 5 polyps, its further occurrences were ignored, resulting in 6 possible levels of abundance for each stage (i. e. occurred in 0 polyps, 1 polyp . . . or, $5+$ polyps).

Lunar Period. Calender dates of samples were assigned a lunar date using moon phases read from The Astronomical Almanac (Anonymous 1980-1982) and The Star Almanac (Anonymous 1983). Day 1 of the cycle was taken to be the first day of new moon.

\section{RESULTS}

Pocillopora damicornis from southwestern Australia is a simultaneous hermaphrodite, with ova and sperm commonly seen in the same polyp. Ovaries were situ- ated on stalks projecting into the coelenteron, as reported for $P$. damicornis from the Great Barrier Reef (Harriot 1983). However, testes appeared as outgrowths of mesenteries, although this was not always apparent in transverse sections of polyps, as not all of a large testis was connected to the mesentery.

Six pairs of gonads were present within a polyp and sperm substantially outnumbered ova in terms of the volume occupied within a polyp, and in the number of polyps with gonads of one sex. The latter result may have been largely an artifact of the former.

\section{Sequence of gametogenesis}

\section{Spermatogenesis}

Four distinct stages of sperm development were identified. Stage I (Fig. 1a). Spermaria usually $<30 \mu \mathrm{m}$ diameter $_{i}$ primary spermatocytes surrounded by a thickened spermatogonial wall. Stage II (Fig. 1b). Testes of varying size (up to $200 \mu \mathrm{m}$ ); secondary spermatocytes with a characteristic 'hollow circle' appearance. Stage III (Fig. 1c). Large (usually $>100 \mu \mathrm{m}$ diameter) testes; densely staining spermatids; testis not vacuolated. Stage IV (Fig. 1d). Mature sperm with tails; the middle of the testis often vacuolated or the whole testis loosely packed with sperm. Stage IV sperm were sometimes observed free in the coelenteron, although this may be due to histological technique. No sperm were seen to be shed from live colonies, either in the field or in aquaria. Neither was any structure seen which resembled a 'spent' testis. Presumably, after sperm are shed, the now thin membraneous covering of the testis is resorbed.

\section{Oogenesis}

Staging of oogenesis was more arbitrary than for spermatogenesis and was primarily based on the size of the oocyte. Four stages were chosen, to reflect: very immature ovaries, the early stages of oocyte development, ova near maturity, and mature ova.

Stage I (Fig. 2a). Multiple oocyte ovary; oocytes $<50 \mu \mathrm{m}$ (smallest oocytes were $10 \mu \mathrm{m}$ in diameter). Stage II (Fig. 2b). Single oocyte ovary; oocytes $<50 \mu \mathrm{m}$, although usually $>30 \mu \mathrm{m}$ diameter. Stage III (Fig. 2c). Oocytes from 50 to $70 \mu \mathrm{m}$ diameter; nucleolus usually well developed and intensely staining, occasionally dispersed throughout the nucleus; granular cytoplasm invested with numerous small vacuoles. Stage IV (Fig. $2 \mathrm{~d}$ ). Oocyte $>70 \mu \mathrm{m}$ diamter (up to $116 \mu \mathrm{m}$ ); usually surrounded by a darker membrane and contracted slightly from the ovary wall; cytoplasmic vacuoles 




Fig. 1. Pocillopora damicornis. Spermatocyte stages. (a) Stage I; SC1: primary spermatocyte; W: spermatogonial wall; (b) Stage II; SC2: secondary spermatocyte; (c) Stage III; ST: spermatid; (d) Stage IV; SP: mature sperm

enlarged; nucleus and nucleolus less obvious than in the previous stage.

The transition from Stage I to Stage II reflects a reduction in the number of oocytes per ovary similar to that reported in the early development of female gonads in Pocillopora damicornis from the Great Barrier Reef (Harriot 1983) and Stylophora pistillata from the Red Sea (Rinkevich \& Loya 1979a). Ovaries started with up to 4 Stage I oocytes which were usually reduced to 1 during the early stages of development. Occasionally, older oocytes, up to Stage IV, could be seen in pairs or triplets. In many cases, an ovary containing a Stage III or IV oocyte would have 1 or 2 small Stage I oocytes developing at its base.

Cytoplasmic vacuoles increased in size during development of the oocyte. These were probably lipid storage areas with the lipid being lost during tissue processing.

\section{Embryogenesis}

No developmental stages connecting the largest ova (116 $\mu \mathrm{m}$ diameter) with the smallest planulae $(160 \mu \mathrm{m}$ length) were detected in any of the 486 sections examined. Planulae of various sizes were found in polyps adjacent to, and sometimes within the same polyp as, those with ova of various sizes from Stage I to IV. However, despite the observation of hundreds of contemporaneous eggs and developing planulae in 29 heads over 2 or 3 cycles of planulation, no cleavage, blastula, or gastrula stages were found.

The smallest planulae detected were oval-shaped, ciliated and had tissue already differentiated into endodermal and ectodermal layers with mesoglea apparent. The most distinctive feature in the recognition of planulae was the characteristic squamous ectodermal cells. Planulae continued to differentiate during brooding, developing mesenteries when ca 200 to $300 \mu \mathrm{m}$ in length and later, when nearing $1000 \mu \mathrm{m}$, developing stomodeum and tentacles (Fig. 3).

\section{Timing of Gametogenesis}

\section{Spermatogenesis}

The most complete set of data for gametogenesis was the PSP series in which collections were taken at intervals of from 4 to $14 \mathrm{~d}$ over approximately 3 to 4 lunar cycles in summer 1982-83 (Fig. 4). Even at this 




Fig. 2. Pocillopora damicornis. Oocyte stages. (a) Stage I: O: early oocyte; (b) Stage II; N: nucleus; C: cytoplasm; (c) Stage III; V: cytoplasmic vacuole; (d) Stage IV

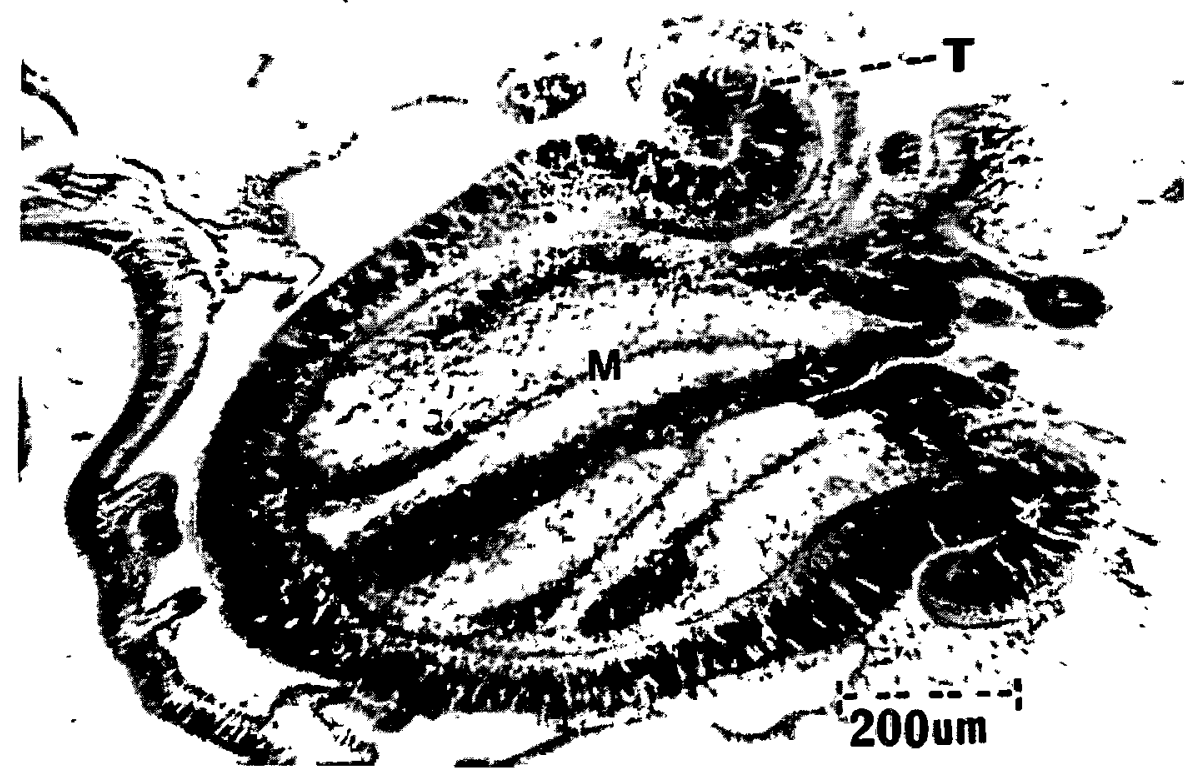

Fig. 3. Pocillopora damicornis. Section through polyp showing fully developed planula with mesenteries $(M)$ and tentacles $(T)$

intensity of sampling, parts of the cycle may be absent and the interpolation between collections made many days apart may be misleading. Despite these gaps, 3 complete cycles of spermatogenesis were clearly visible in plots of the average abundances of the stages.
The period between consecutive peaks or lows of the cycle for each sperm stage was visually estimated from these plots and the average of 18 such estimates was $31.3 \mathrm{~d}$ (s. d. 5.18 d), which was not significantly different from the lunar period of $29.5 \mathrm{~d}$. In spite of the 



(B)

Fig. 4. Pocillopora damicornis. Abundance of the 4 stages of sperm, averaged over all heads from collections, at (A) Salmon Point (PSP series) and (B) Mary Cove (PMC series) for summer 1982-1983. Lunar days and calender months appearing along lower axis of (A) also apply to (B). $\bullet$ Stage I; $\times$ Stage II; O Stage III; $\square$ Stage IV

constraints of limited sampling, most stages of spermatogenesis were seen to have regular and distinct timing of peaks and lows, with Stage I starting its cycle while Stage IV was at its peak. The pattern of a composite cycle drawn from all collections was consistent with the summer 1982-83 cycles. In the composite cycle, maximum abundances of the 4 stages occurred in the order Stage I-Stage II (Day 11), Stage III (Day 24), and Stage IV (Day 28).

\section{Oogenesis}

Cycles of oogenesis were less obvious than those of spermatogenesis, primarily as there was less variation within stages between collections. This may be due to a more continuous production of some stages, or to the more arbitrary delineation of stages. Some peaks were apparent in plots of the average abundances (especially for Stage III) and again these followed a lunar cycle. Stage IV ova were rarely encountered and presumably occupied a short period in the cycle. The composite cycle was not easily resolved into a time sequence for stages of ova, perhaps due, in part, to between-cycle and between-season variation.

Comparison of cycles of oogenesis and spermatogenesis suggested the synchronous development of sperm and ova rather than one maturing before the other. This was particularly apparent for the Stage III gametes, with ova peaking on Day 26 of each of the 3 reproductive cycles followed intensively in the summer of 1982-83, and sperm on Days 18 to 25, 26 and 27 .

\section{Planulae}

The presence of planulae within a sample was usually obvious, as medium to large planulae completely filled the coelenteron of a polyp. Although planulae most commonly occurred singly, polyps with 2 or 3 mature planulae were sometimes found and on one occasion, a polyp with 6 planulae was found. The distension of polyps by planulae caused the live coral to develop a dark-spotted appearance when near planulation. As a test of the efficacy of histology in detecting planulae, the results of overnight shedding tests were compared to the results of histology for each head in these collections. Planulae were shed in 34 of 82 tests, and histological analysis revealed planulae in all but 3 of these tests. Additionally, histology revealed planulae in 21 heads of the 48 which did not shed planulae; presumably these were immature planulae.

Planulae were detected only in 18 samples collected between lunar Days 13 and 1. The proportion of individuals containing planulae in a collection increased over this period from about $23 \%$ to a maximum of about $85 \%$ at Day 27 but then dropped rapidly to 10 to $15 \%$ by Days 29 and 1 . A comparison of data for the 
$4 \mathrm{yr}, 1980$ to 1983, from collections taken during this period when planulae were likely to be present (lunar days 13 to 1 inclusive), showed collections from the summer months (late Dec to early Apr) to be much more likely to contain planulae than collections from the rest of the year $(\mathrm{p}<0.001$, Chi-Squared Test): 17 of 26 collections in the summer had planulae, but only 1 of 18 collections in the winter had planulae. In the single collection containing planulae outside the summer months, only 1 head of 11 collected had planulae. Thus, the production of planulae had both a lunar and a seasonal component. If records of gametogenesis from all parts of the lunar cycle were examined for the same seasonal divisions a similar, but less pronounced, trend was evident: all 32 collections in summer had gametogenesis, but 7 of the 28 collections in winter failed to show gametogenesis $(p<0.01$ Chi-Squared Test).

Planulae were detected frequently in the same head on a number of consecutive occasions during a single cycle. By comparing the maximum sizes of planulae seen in a head on consecutive collections, it was possible to estimate their growth rates. Estimates using the heads of collections taken from Salmon Point on 31 Jan, 4 Feb and 9 Feb, 1983 (PSP 10, 11, 12) yield an average daily growth rate of $59.3 \mu \mathrm{m}$ (s.d. $47.5 \mu \mathrm{m}$, $\mathrm{n}=11$ ) for the first period and $64.6 \mu \mathrm{m}$ (s.d. $36.4 \mu \mathrm{m}$, $\mathrm{n}=15$ ) for the second. Estimates of growth rates of planulae from the Mary Cove site (PMC series) taken over similar periods, were more variable between periods $(92.3 \mu \mathrm{m}$ (s.d. 11.1, $\mathrm{n}=3$ ) and $44.4 \mu \mathrm{m}$ (s.d. $36.7, \mathrm{n}=6$ ), but with an average of $60.4 \mu \mathrm{m}$, quite comparable.

Taking an average growth rate for both sites of $61.8 \mu \mathrm{m} \mathrm{d}^{-1}$ and assuming that growth was linear, it would take the smallest planulae $(160 \mu \mathrm{m}) 21 \mathrm{~d}$ to grow to the size of the largest $(1440 \mu \mathrm{m})$, or $15 \mathrm{~d}$ to the average maximum of the two 9 Feb collections $(990 \mu \mathrm{m})$. Within single cycles, planulae were seen commonly in the same head for up to $15 \mathrm{~d}$, although the variation in developmental stage seen at any one time meant that these could encompass several 'waves' of planulae. Indeed, planulae were seen to be shed at both sites in both the 4 Feb and 9 Feb collections.

The relation between timing of oogenesis and embryogenesis was puzzling. In what was probably the first cycle likely to produce planulae for the 1982-83 season in the PSP and PMC series, mature ova and sperm were seen in profusion in 28 of 31 heads over Days 18, 24 and 28 for PSP and Days 18 and 24 for PMC (no sample was taken of PMC on Day 28) without the appearance of a single planula. Planulae were first

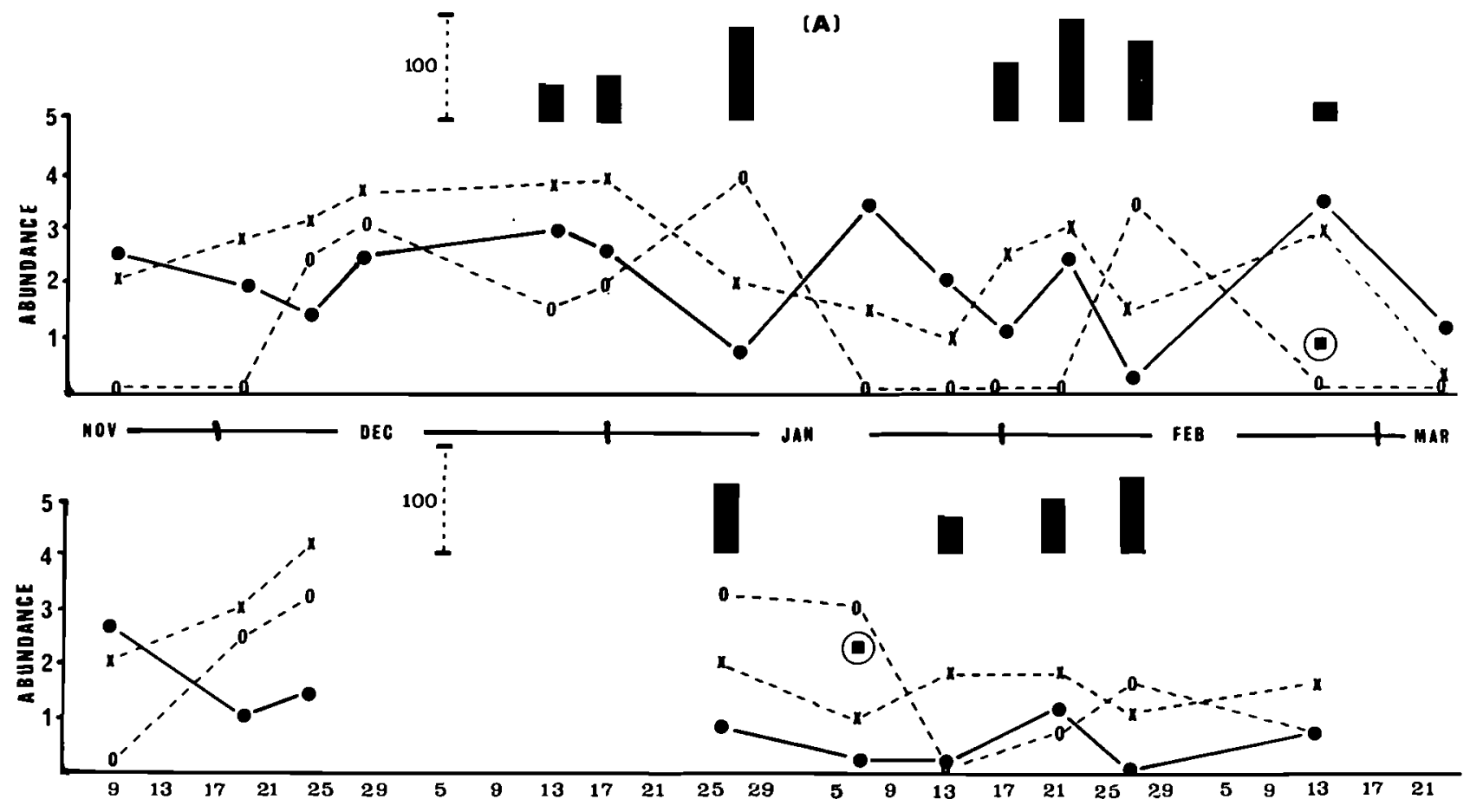

[B]

Fig. 5. Pocillopora damicornis. Abundance of the 4 stages of oocytes, averaged over all heads from collections, at (A) Salmon Point (PSP series) and (B) Mary Cove (PMC series) for summer 1982-1983. Lunar days and calender months appearing along the lower axis of (A) also apply to (B) and vice versa. $\bullet$ Stage $\mathrm{I}_{;} \times$Stage II; O Stage III; $\square$ Stage IV. Solid bars above both graphs: \% of heads in a sample found with planulae (scale bar $=100 \%$ ) 
seen in Day 13 of the following cycle, where they appeared most commonly in heads in which ova past Stage II and sperm past Stage III were not seen to develop until after a further $4 \mathrm{~d}$ (Fig. 4, 5, 6 \& 7). In the following cycles of this summer, planulae developed either before mature gametes (PSP) or without any detectable gametes (PMC). As stages containing only immature gametes were found between successive occurrences of mature gametes and planulae, it is improbable that the gametes of one cycle produced the planulae of the next, unless the early stages of embryogenesis were unrecognizable as such, or developed externally.

\section{Synchrony}

\section{Within-site}

Visual comparisons of gametogenesis between heads within the Salmon Point and Mary Cove sites (Fig. 6 \& 7) showed that if heads were producing gametes, both the stage and abundance of these gametes were similar. In an attempt to produce a statistic which would allow objective testing of synchrony, the average dissimilarity between the histograms of Fig. $6 \& 7$ was calculated. If abundance and stage of gametes in an individual are uncorrelated with those of other individuals, this statistic should not be significantly different from $50 \%$. As it makes no allowance for the cyclic nature of reproduction or the extent of nil values within a histogram, this is not a particularly sensitive test, and may underestimate synchrony. To standardize for sample size, only 11 heads of the PSP series, chosen randomly, were used in calculations. After arcsin transformations, these returned values of 25.7 (s.d. 4.38) for sperm and 27.3 (s.d. 3.00) for ova. Values for PMC were 24.1 (s. d. 5.60) for sperm and 24.8 (s.d. 6.42) for ova. There are no significant differences between these values (KruskallWallis Test) and all are significantly less than $50 \%$ ( $\mathrm{p}<0.001, \mathrm{~T}$-test).

\section{Between-site}

Average dissimilarity calculated between sites for the 9 occasions when both sites were sampled simultaneously was 34.7 (s.d. 5.31) for sperm and 31.0 (s.d. 3.67) for ova; again using a random sample of 11 heads from PSP. These values are also below $50 \%(p<0.001$, T-test) but are significantly greater than those of the single-site values $(p<0.001$, Mann-Whitney U Test). This may be due to the earlier cessation of reproduction in some of the Mary Cove (PMC) individuals. Fig. $6 \& 7$ show clearly that during the first summer cycle (Nov-Dec) both sites had very similar cycles. However, after the first period of planulation with peak gonad development (early Jan), gametogenesis in the Mary Cove population largely ceased. In 2 subsequent cycles, less than $50 \%$ of heads developed ova and less than $60 \%$ sperm in the first, then $30 \%$ and $20 \%$, respectively in the second.

\section{Multiple reproduction}

Sequential planulation over the summer was the normal pattern of reproduction with $19 \%$ of tagged heads developing 3 batches of planulae, $61 \%$ two batches, $13 \%$ one batch and $6 \%$ none.

Although the frequency of planulation was similar between the PSP and PMC series, the PSP heads showed multiple cycles of gametogenesis, while many of the PMC heads ceased to produces gametes after Jan.

\section{DISCUSSION}

\section{Developmental origins of planulae}

Despite an intensive histological study of gametogenesis, the developmental pathway leading to a brooded planula remains equivocal. While all coral heads which produced planulae also produced gametes, developmental stages connecting gametes and planulae were not found. Indeed, for all coral heads examined sequentially, planulae appeared before gametogenesis was complete in at least one reproductive cycle, and in 8 of these, planulae were found without apparent oogenesis in the preceding $29 \mathrm{~d}$. Early embryogenesis has never been reported in studies of gametogenensis for Pocillopora damicornis (Harrigan 1972, Harriot 1983, Martin Chavez unpubl.) or for any coral which broods its young (Rinkevich \& Loya 1979a, b, Kojis \& Quinn 1981b, Fadlallah \& Pearse 1982a). One interpretation of these features is that the origin of these brooded planulae does not involve the internal development of ova.

Nevertheless, several aspects of the present histological study are consistent with an origin of planulae from ova. These are: the absence of planulae from heads in which gametes were never seen; similar seasonal trends in gametogenesis and the production of planulae; the high ratio of sperm to ova (which would be predicted for ova fertilized internally by externally shed sperm); the occurrence of multiple planulae in a polyp in numbers of up to 6 (the number of ovaries per polyp). The absence of stages connecting ova and planulae may have been due to a rapid development of fertilized ova to ciliated larvae. If sperm were released in the evening or at night and development was 

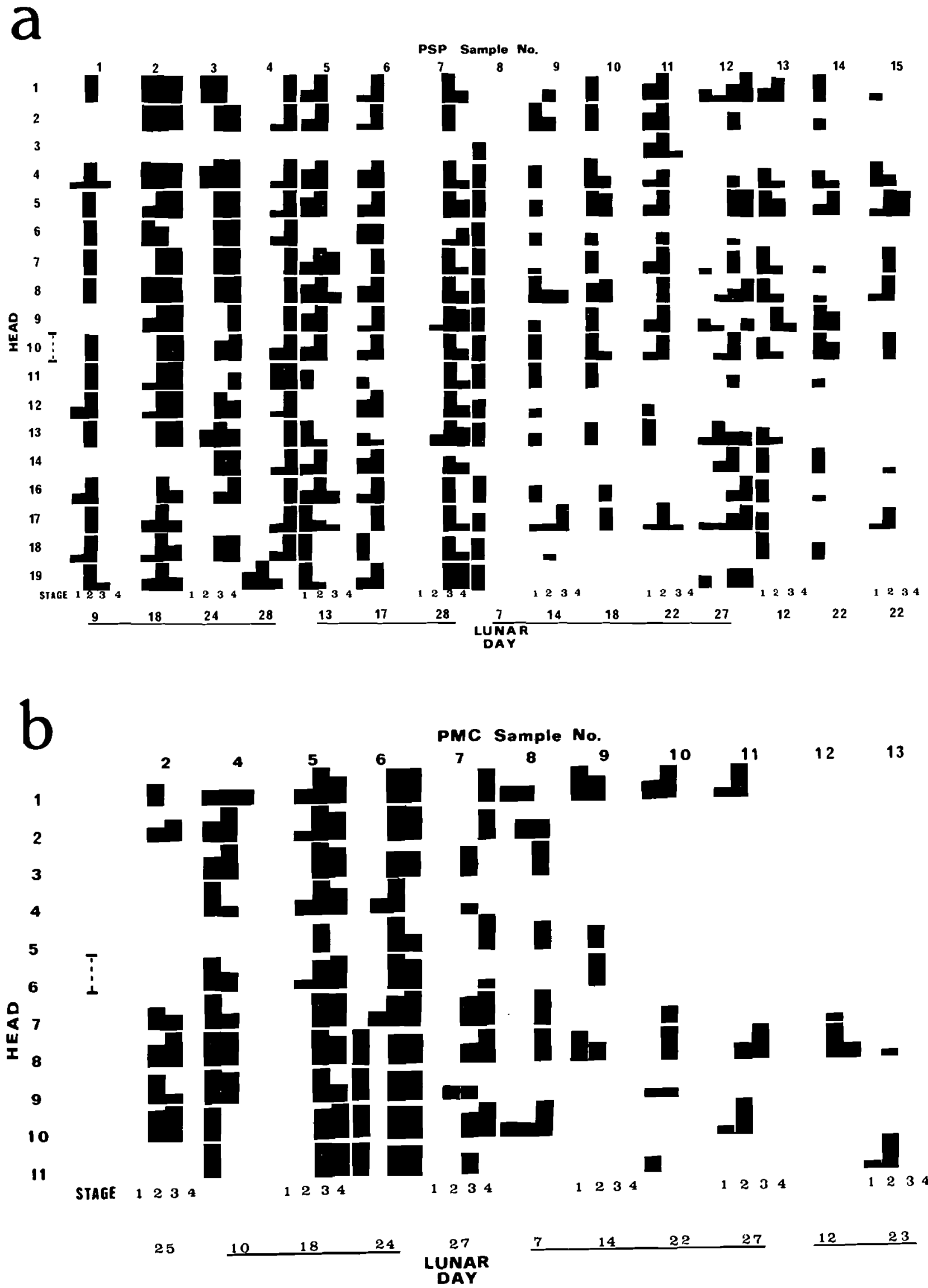

Fig. 6. Pocillopora damicornis. Abundance of the 4 stages of sperm. Scale bar at left of figure is set to 5 units, the maximum. (a) 18 of the 20 heads for the 15 samples of the PSP series; heads 15 and 20 were never found with gametes; (b) 11 heads for 11 of the 13 samples of the PMC series; no gametes were found in Sample 1 and the tissues of Sample 3 could not be assigned to individuals. In both (a) and (b), lunar days. of the same cycle are connected by underlining 


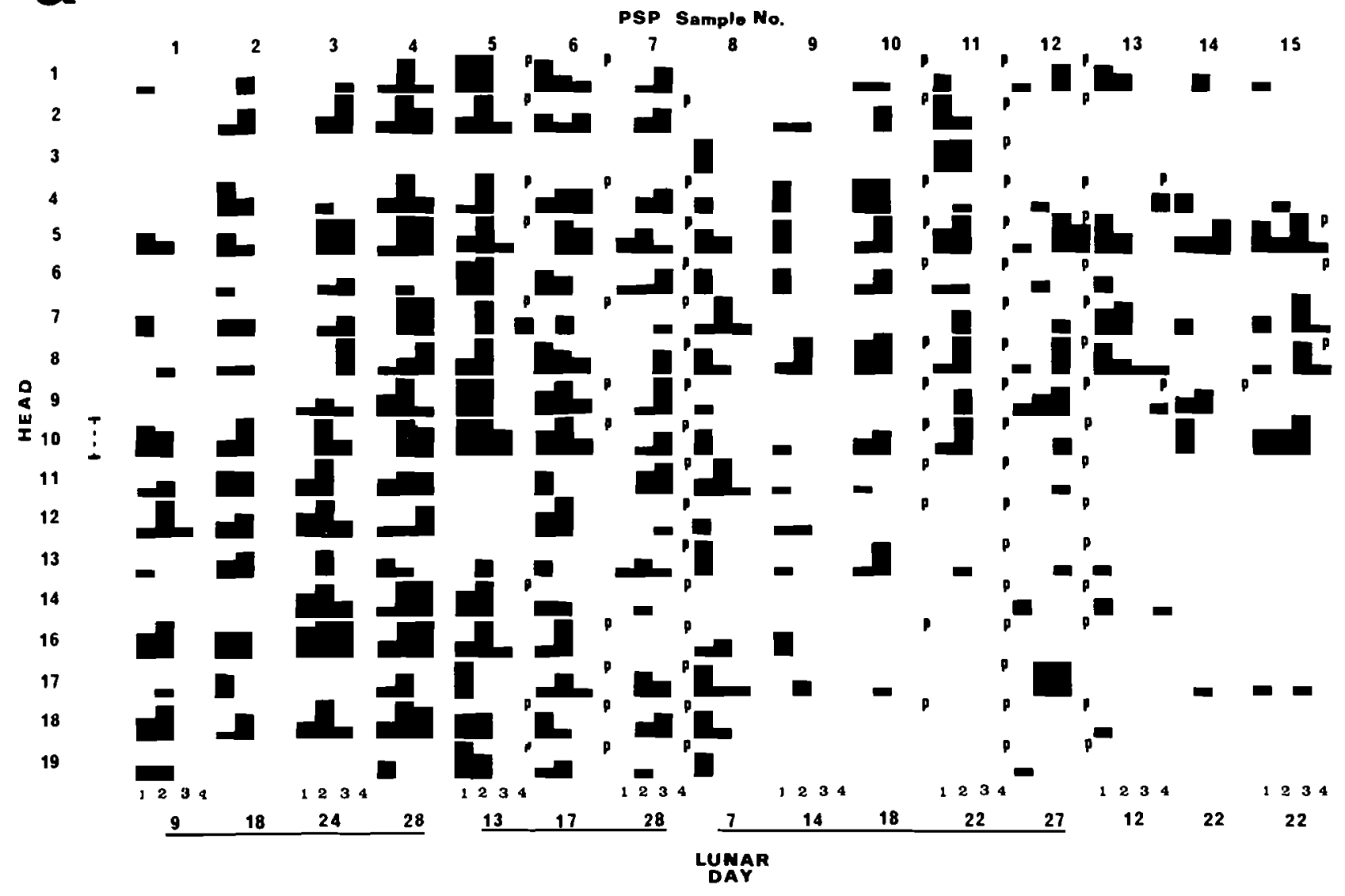

b

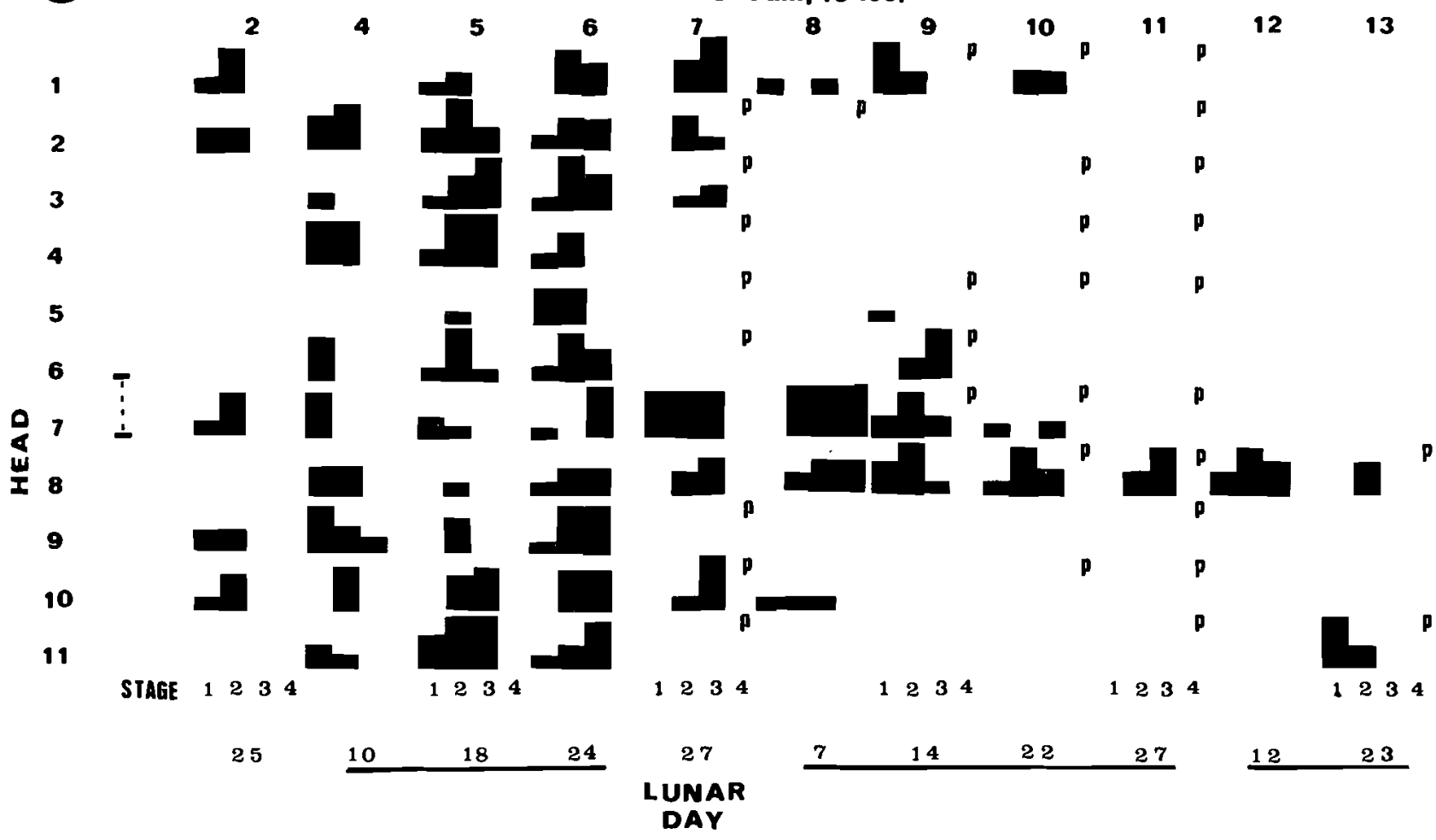

Fig. 7. Pocillopora damicornis. Abundance of the 4 stages of oocytes. Scale bar at left of figure is set to 5 units, the maximum. (a) 18 of the 20 heads for the 15 samples of the PSP series; heads 15 and 20 were never found with gametes; (b) 11 heads for 11 of the 13 samples of the PMC series; no gametes were found in Sample 1 and the tissues of Sample 3 could not be assigned to individuals. In both (a) and (b), lunar days of the same cycle are connected by underlining 
abrupt, samples taken during the day may not have contained early developmental stages. Externally fertilized ova of Astrangia danae develop into larvae within 6 to $8 \mathrm{~h}$ (Szmant-Froelich et al. 1980). In contrast to this, most other reports of the development of externally fertilized ova to ciliated larvae suggest a longer period. Times vary from around $24 \mathrm{~h}$ for Porites andrewsi (Kojis \& Quinn 1981b) and Paracyathus stearnsi (Fadlallah \& Pearse 1982b) to near $48 \mathrm{~h}$ for Goniastrea cf. flavulus (Kojis \& Quinn 1981a) and Caryopyllia smithi (Tranter et al. 1982). If developmental times for Pocillopora damicornis embryos are similar to these instances, the current intensity of sampling should have revealed pre-gastrula stages. An alternative explanation for the absence of early embryogenesis may be that its stages were unrecognizable as reproductive structures until the squamous ectoderm, characteristic of planulae, appeared. In summary, the total absence of stages connecting ova and planulae of $P$. damicornis appears to outweigh the circumstantial evidence in favour of the internal development of ova to form planulae.

\section{Seasonal and lunar patterns}

If Pocillopora damicornis from Rottnest Island is at all representative of corals which brood young, the variation in gametogenesis and planulation recorded here between sites, heads and samples stresses the need for caution in interpreting the results of other reproductive studies. Unless sampling designs take account of both lunar and seasonal cycles of gametogenesis and planulation, variation in either cycle could obscure the existence of both. Planulation of $P$. damicornis from the Great Barrier Reef is recorded as having a lunar periodicity which varies with season (Marshall \& Stephenson 1933, Harriot 1983), but a seasonal component to abundance is only reported by the latter author. This disagreement may result from disparate sampling regimes, as the comparison of samples from different seasons will be misleading unless they are taken at appropriate periods in the lunar cycle. Values for the proportion of heads found planulating during a given study, such as $39 \%$ for Harrigan (1972) and $16 \%$ for Harriot (1983) are probably meaningless without the exact collection times, with respect to lunar phase and season.

A number of lunar cycles of planulation are reported to occur without any influence of season on phase, for Pocillopora damicornis from Hawail and Enewetak (Richmond \& Jokiel 1984). Two morphs (each composed of a number of clones; Stoddart in press) which occur on the same reef in Kaneohe Bay, Oahu, Hawaii, exhibit distinctly different lunar timing of planulation which reacts differently to changes in environmental parameters (Richmond \& Jokiel 1984). The synchrony of development of gametes and planulation seen in reproductively active heads for this study discount such a polymorphic response to lunar phase in $P$. damicornis from southwestern Australia. However, both heads which did not produce gametes or planulae (PSP 15 and 20) and those which were rarely found in reproductive condition (PSP 3 and 19) all possessed the same genotype. This genotype was not shared with any other head studied reproductively and histologically. Thus, a pervasive effect of genotype on reproduction may be present in $P$. damicornis from both southwestern Australia and Hawaii.

As Pocillopora damicornisfrom southwestern Australia planulates strictly seasonally, with a single fixed lunar periodicity for planulation and gametogenesis within and between sites, its reproductive pattern is distinct from that of $P$. damicornis from the Great Barrier Reef and Hawaii. Its period of peak planulation, last quarter to new moon, is similar to type ' $\mathrm{Y}$ ' $P$. damicornis from Hawaii (Richmond \& Jokiel 1984) and August-November records from the Great Barrier Reef (Marshall \& Stephenson 1933, Harriot 1983). The massive production of both gametes and planulae by the corals of this study differentiates them from $P$. damicornis of the eastern Pacific which have been inferred to be largely inactive in gametogenesis and planulation (Richmond 1981, Highsmith 1982) on the basis of a lack of larval settlement (Birkeland 1977). Thus it seems that no 2 studies of $P$. damicornis reproduction yield similar patterns, a result which could be due to dissimilar environments, distinct gene pools, or differing methods and criteria for measuring reproductive performance.

Jokiel \& Guinther (1978) demonstrate sensitivity of planulation levels in Pocillopora damicornis from Hawaii to shifts in temperature of as little as $1 \mathrm{C}^{\circ}$, with an optimum of 26 to $27^{\circ} \mathrm{C}$. Therefore, seasonality in planulation may be primarily mediated by variation in sea temperature. The present study was conducted in an area with a large seasonal variation in sea temperature (over $10 \mathrm{C}^{\circ}$ ) where corals planulated at times of maximum water temperature, probably 25 to $26^{\circ} \mathrm{C}$ (Stoddart 1984b). Seasonal variation in water temperature is less marked at Lizard Island, the site of Harriot's study, where there is a range of $4 \mathrm{C}^{\circ}$ (Kinsey 1977). Yet, there is a substantial seasonal component to the abundance of planulae, with minimum abundances coincident with minimum sea temperatures (Harriot pers. comm., April 1983). In contrast, the year-round planulation of $P$. damicornis in Kaneohe Bay, Hawaii (Harrigan 1972, Stimson 1978, Richmond \& Jokiel 1984) occurs over a $7.7 \mathrm{C}^{\circ}$ range (Richmond \& Jokiel 1984), while at Enewetak, Marshall Islands, with a 
seasonal temperature variation of $4.8 \mathrm{C}^{\circ}$ (Richmond \& Jokiel 1984), the number of heads planulating in summer is almost double that in winter (Stimson 1978). Thus, although environmental parameters may differ between study sites, these differences do not fully explain the distinct reproductive patterns of $P$. damicornis populations from these sites.

Two options available to polyps at non-optimal temperatures are, either increase the period of the cycle of gametogenesis, or cease reproduction and abort or resorb the gametes. The former option may result in the phase shift reported for Great Barrier Reef populations, although more intensive sampling is needed to document this shift adequately. The increase in the proportion of heads seen without gametes in the PMC series during the latter stages of the 1982-83 reproductive season may reflect the second option.

Confirmation of multiple reproduction within a season by discrete coral heads pushes the level of analysis down a further step. Do polyps reproduce more than once per season? As rarely more than $60 \%$ of polyps in any single histological section contained gametes or planulae, the answer may be 'No'. However, the sampling design to test such an hypothesis will not be able to use a technique such as histology, which precludes repeated sampling to the same polyp.

In summary then, this study of gametogenesis and planulation in Pocillopora damicornis at its southern limit of distribution in Western Australia revealed that: (1) spermatogenesis and oogenesis occur concurrently within heads but are not necessarily precursors of planulation; (2) gametogenesis and planulation occur mainly in spring-summer (Nov-Mar) and follow a lunar cycle ${ }_{i}(3)$ reproductive cycles are synchronized within and, to a lesser extent, between sites; (4) individual coral heads may have several (up to 3 ) cycles of maturing gametes and planulae per season.

Acknowledgements. Research funding for this study was provided by a University of Western Australia Postgraduate Research Grant to J.A.S., and acommodation by the Rottnest Island Biological Research Station. We thank D. J. Ayre, S. Thompson and M. S. Johnson for assistance with collection of samples and S. Hopwood for photography. This is a contribution from the Marine Biological Laboratory of the University of Western Australia.

\section{LITERATURE CITED}

Anonymous (1980-1982). The astronomical almanac. U.S Govt Printing Office, Washington

Anonymous (1983). The star almanac. H. M. Stationery Office, London

Birkeland, C. (1977). The importance of rate of biomass accumulation in early successional stages of benthic com- munities to the survival of coral recruits. Proc. 3rd Int. Coral Reef Symp. 1: 15-22

Black, R., Johnson, M. S. (1979). Asexual viviparity and population genetics of Actinia tenebrosa. Mar. Biol. 63: 27-31

Campbell, R. D. (1974). Cnidaria. In: Giese, A. C., Pearse, J. S. (ed.) Reproduction of marine invertebrates, Vol. 1, Acoelomate and pseudocoelomate metazoans. Academic Press, New York, p. 133-199

Connell, J. H. (1973). Population ecology of reef building corals. In: Jones, O. A., Endean, R. (ed.) Biology and geology of coral reefs, Vol. 2, Biology 1. Academic Press, New York, p. 205-245

Fadlallah, Y. H. (1983). Sexual reproduction, development and larval biology in scleractinian corals. Coral Reefs 2 : $129-150$

Fadlallah, Y. H., Pearse, J. S.( 1982a). Sexual reproduction in solitary corals: overlapping oogenic and brooding cycles, and benthic planulas in Balanophyllia elegans. Mar. Biol. 71: $223-231$

Fadlallah, Y. H., Pearse, J. S. (1982b). Sexual reproduction in solitary corals: synchronous gametogenesis and broadcast spawning in Paracyathus stearnsii. Mar. Biol. 71: 237-239

Harrigan, J. F. (1971). The planula larvae of Pocillopora damicornis: lunar periodicity of swarming and substrate selection behaviours. Ph. D. thesis, University of Hawaii, Honolulu

Harriot, V. M. (1983). Reproductive seasonality, settlement, and post-settlement mortality of Pocillopora damicornis (Linnaeus), at Lizard Island, Great Barrier Reef. Coral Reefs 2: 151-157

Harrison, P. L., Babcock, R. C., Bull, G. D., Oliver, J. K., Wallace, C. C., Willis, B. L. (1984). Mass spawning in tropical reef corals. Science 223: 1187-1189

Highsmith, R. C. (1982). Reproduction by fragmentation in corals. Mar. Ecol. Prog. Ser. 7: 207-228

Hyman, L. (1940). The invertebrates. I. Protozoa through Ctenophora. McGraw-Hill Co., New York.

Jokiel, P. L., Guinther, E. B. (1978). Effects of temperature on reproduction in the hermatypic coral Pocillopora damicornis. Bull. mar. Sci. 33: 181-187

Kinsey, D. W. (1977). Seasonality and zonation in coral reef productivity and calcification. Proc. 3rd Int. Coral Reef Symp. 2: 383-388

Kojis, B. L., Quinn, N. L. (1981a). Aspects of sexual reproduction and larval development in the shallow water hermatypic coral Goniastrea australensis (Edwards and Haime, 1857). Bull. mar. Sci. 31: 558-574

Kojis, B. L., Quinn, N. L. (1981b). Reproductive strategies in a few species of Porites (Scleractinia). Proc. 4th lnt. Coral Reef Symp. 1: 145-151

Marshall, S. M., Stephenson, T. A. (1933). The breeding of reef animals. Pt I The corals. Sci. Rpts Gt Barrier Reef Exped. 3: 219-245

Orr, J., Thorpe, J. P., Carter, M. A. (1982). Biochemical genetic confirmation of the asexual reproduction of brooded offspring in the sea anemone Actinia equina. Mar. Ecol. Prog. Ser. 7: 227-229

Richmond, R. H. (1981). Energenetic considerations in the dispersal of Pocillopora damicornis (Linnaeus) planulae: Proc. 4th int. Coral Reef Symp. 1: 153-156

Richmond, R. H., Jokiel, P. L. (1984). Lunar periodicity in larva release in the reef coral Pocillopora damicornis at Enewetak and Hawaii. Bull. mar. Sci. 34: 280-287

Rinkevich, B., Loya, Y. (1979a). The reproduction of the Red Sea coral Stylophora pistillata. I. Gonads and planulae. Mar. Ecol. Prog. Ser. 1: 133-144

Rinkevich, B., Loya, Y. (1979b). The reproduction of the Red 
Sea coral Stylophora pistillata. II. Synchronization of breeding and seasonality of planulae shedding. Mar. Ecol. Prog. Ser. 1: 145-152

Rosen, B. R. (1981). The tropical high diversity enigma - the coral's eye view. In: Chance, change and challenge. The evolving biosphere. Florey, P. L. (ed.) British Museum (Natural History) and Cambridge University Press, Cambridge, p. 103-129

Stimson, J. S. (1978). Mode and timing of reproduction in some common hermatypic corals of Hawaii and Enewetak. Mar. Biol. 48: 173-184

Stoddart, J. A. (1983). Asexual production of planulae in the coral Pocillopora damicornis. Mar. Biol. 76: 279-284

Stoddart, J. A. (1984a). Genetical structure within populations of the coral Pocillopora damicornis. Mar. Biol. 81: 19-30
Stoddart, J. A. (1984b). The genetical structure of populations of the coral Pocillopora damicornis. Ph. D. thesis, University of Western Australia, Perth, Western Australia

Stoddart, J. A. (in press). Biochemical genetics of Pocillopora damicornis in Kaneohe Bay, Oahu, Hawaii. In: Coral reef population biology. Jokiel, P. L., Richmond, R. H. (ed.) Hawaii Inst. Mar. Biol., Technical Report

Szmant-Froelich, A. P., Yevich, P., Pilson, M. E. Q. (1980). Gametogenisis and early development of the temperate coral Astrangia danae (Anthozoa : Scleractina). Biol. Bull. mar. biol. Lab., Woods Hole 158: 257-269

Tranter, P. R. G., Nicholson, D. N., Kinchington, D. (1982). A description of spawning and post-gastrula development of the cool temperate coral Carvophyllia smithi. J. mar. biol. Ass. U.K. 62: 845-854

This paper was presented by Professor J. S. Pearse; it was accepted for printing on February 19, 1985 